\title{
Recent Approaches for Mycetoma Management in Iran
}

\author{
Kazemi $A^{1}$, Ahmadkhani $F^{2}$, Zarei Mahmoudabadi $A^{3}$ and Fattahi \\ $\mathrm{A}^{4 *}$ \\ ${ }^{1}$ Medical Philosophy and History Research Center, Tabriz University of Med. Sci., \\ Tabriz, Iran
}

${ }^{2}$ Department of Medical Mycology and Parasitology, School of Public Health, Tehran

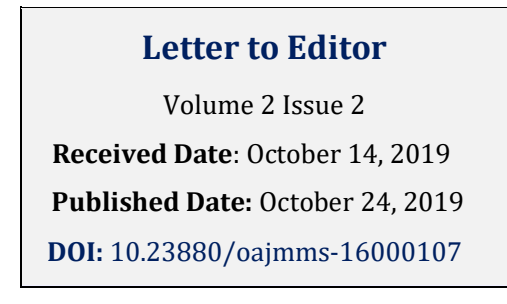

University of Med. Sci., Tehran, Iran

${ }^{3}$ Department of Medical Mycology, Faculty of Medicine, Infectious and Tropical Diseases Research Centre, Jundishapur University of Med. Sci., Ahvaz, Iran

${ }^{4}$ Center for Research and Training in Skin Diseases and Leprosy, Tehran University of Med. Sci., Tehran, Iran

*Corresponding Author: Azam Fattahi, Center for Research and Training in Skin Diseases and Leprosy, Tehran University of Medical Science, Iran, ORCID: 0000-0003-3613-4644; Email: afattahi@sina.tums.ac.ir

Keywords: Iran; Actinomycoticmycetoma; Eumycoticmycetoma; Country registration

\section{Letter to Editor}

Mycetoma is a chronic granulomatous disease of the cutaneous and subcutaneous tissues that is associated with multiple sinuses producing pus, blood and granules, painless swelling and diffusion to adjacent tissues, including bone [1]. Therefore, in the long run, the disease is associated with disability and severe complications and can lead to death if left untreated [2]. The infection is caused by a wide range of exogenous geophilic organisms, including aerobic actinomycetes and saprophytic fungi [3]. Although it has a worldwide distribution, it is mainly found in tropical and subtropical regions with low rainfall [4].

Precise statistics on its prevalence and global incidence have not been well established so far, and in many endemic and sporadic countries there is no proper surveillance system to control and record cases, and many cases are limited to case reports. Mycetoma is one of the rare diseases in Iran and its cases have been reported sporadic. Between 1972-2009, 36\% of the northern provinces and $27 \%$ of the southern provinces reported the disease [5].
Recent studies show that out of the total of 129 reported cases of mycetoma in Iran in the past 55 years, actinomycetoma (75.2\%) has more than the eumycetoma (24.8\%). Most and least agents of Actinomycetoma, Nocardia asteroides (28.3\%), Nocardia brasiliensis and Streptomyces somaliensis $(4.3 \%)$ and most and least agents of eumycetoma were reported by Pseudallescheria boydii (41\%) and Madurella mycetomatis (7\%). (Source: First Mycetoma Symposium).

Due to the geographical extent of the disease, in 2016 the World Health Organization (WHO) approved it as Neglected Tropical Disease (NTD) and attempted to control and eliminates it.

In February 2019, the 6th International Mycetoma Congress, in collaboration with the Mycetoma Research Center in Sudan, the World Health Organization and the countries that have been reported mycetoma, aims achieve the right extent of mycetoma in the world and to eradicate it for 2030 .

In this regard, the first symposium to investigate the spread of mycetoma in Iran and set the goals to control the disease with the cooperation of the Ministry of Health in the presence of dermatology, medical mycology, microbiology, pathology and infectious disease professors 


\section{Open Access Journal of Mycology \& Mycological Sciences}

of different provinces of Iran were held at Center for Research and Training in Skin diseases and Leprosy on July 17, 2019.

$>$ The main topics of this symposium included

Addressing the burden of the disease in Iran

$>$ Creation of country mycetoma registry

To adopt the Center for Research and Training in Skin diseases and Leprosy call for action on mycetoma

$>$ To draft milestones and goals for control of mycetoma

Increasing awareness of the public health significance of mycetoma

A review of the scientific knowledge associated with mycetoma (Disease, epidemiology, diagnosis and treatment), sharing experiences and perspectives on this subject.

\section{Important achievements of the first national} symposium on mycetoma include:

$>$ Appropriate case management with emphasis on uncommon forms of the disease

> Utilization of imaging methods, laboratory diagnosis based on medical mycology, microbiology and pathology

$>$ Country Registration for Mycetoma

$>$ Good collaboration and links established between medical centers and laboratories affiliated with medical universities in different provinces for disease management

Decision making approach about mycetoma treatment according Salzburg Declaration

\section{References}

1. Ahmed AO, Van Leeuwen W, Fahal A, Van de Sande W, Verbrugh H, et al. (2004) Mycetoma caused by Madurella mycetomatis: a neglected infectious burden. Lancet Infect Dis 4(9): 566-574.

2. Fahal AH, Vande Sandy WW (2012) The Epidemiology of mycetoma. Current Fungal Infection Reports 6(4): 320-326.

3. Aounallah A, Boussofara L, Ben Said Z, Ghariani N, Saidi W, et al. (2013) Analysis of 18 Tunisian cases of mycetoma at the Sousse hospital (1974-2010). Bull Soc Pathol Exot 106(1): 5-8.

4. Bakhiet SM, Fahal AH, Musa AM, El Mohamed SW, Omer RF, et al. (2018) A holistic approach to the mycetoma management. PLoS NTD 12(5).

5. Khodaveisi S, Shokoohi T, Mahmoudabadi AZ (2008) Review on mycetoma in northern Iran. Journal of Mazandaran University of Medical Sciences 20(76): 96-100. 